\title{
SYNERGETIC EFFECTS OF ALIGNED CARBON NANOTUBE INTERLAMINAR REINFORCEMENT AND THIN PLIES IN COMPOSITE LAMINATES
}

\author{
Estelle Kalfon-Cohen ${ }^{1}$, Reed Kopp ${ }^{1}$, Carolina Furtado ${ }^{1,3,4}$, XinchenNi ${ }^{2}$, Albertino Arteiro ${ }^{3,4}$, \\ Gregor Borstnar $^{5}$, Mark N. Mavrogordato ${ }^{5}$, I. Sinclair ${ }^{5}$, S. Mark Spearing, ${ }^{5}$ Pedro P. Camanho ${ }^{3,4}$, \\ and Brian L. Wardle ${ }^{1}$ \\ ${ }^{1}$ Department of Aeronautics and Astronautics, Massachusetts Institute of Technology,77 \\ Massachusetts Avenue, Cambridge, MA 02139 USA \\ ${ }^{2}$ Department of Mechanical Engineering, Massachusetts Institute of Technology, 77 \\ Massachusetts Avenue, Cambridge, MA 02139 USA \\ ${ }^{3}$ DEMec, Faculdade de Engenharia da Universidade do Porto,Rua Dr. Roberto Frias, s/n, 4200- \\ 465 Porto, Portugal \\ ${ }^{4}$ INEGI, Instituto de Ciência e Inovação em Engenharia Mecânica e Engenharia Industrial,Rua \\ Dr. Roberto Frias, 400, 4200-465 Porto, Portugal \\ ${ }^{5}$ Faculty of Engineering and the Environment, University of Southampton, Highfield, \\ Southampton, SO17 1BJ, UK
}

Keywords: Thin-ply laminate, Carbon nanotube, Mechanical properties, Finite element analysis

\begin{abstract}
Thin-ply carbon fiber laminates have exhibited superior mechanical properties and damage resistance when compared to standard thickness plies, and enable greater flexibility in laminate design. However, the increased ply count in thin-ply laminates also increases the number of plyply interfaces, thereby increasing the number of relatively weak and delamination-prone interlaminar regions. In this study, we report the first experimental realization of aligned carbon nanotube interlaminar reinforcement of thin-ply unidirectional prepreg-based carbon fiber laminates, in a hierarchical architecture termed 'nanostitching'. We synthesize a baseline effective standard thickness laminate using multiple thin plies of the same orientation to create a ply block, and we find an $\sim 15 \%$ improvement in the interlaminar shear strength via short beam shear strength testing for thin-ply nanostitched samples when compared to the baseline. This demonstrates a synergetic strength effect of nanostitching ( $\sim 5 \%$ increase $)$ and thin-ply lamination ( $10 \%$ increase). Synchrotron-based computed tomography of post mortem SBS
\end{abstract}


specimens suggest a different trajectory and mode of damage accumulation in nanostitched thinply laminates, notably the complete suppression of delaminations in the nanostitched region. Finite element predictions of damage progression highlight the complementary nature of positive thin-ply and nanostitching effects that are consistent with an $\sim 15 \%$ improvement in Mode I and II interlaminar fracture toughness due to the aligned carbon nanotubes incorporated at thin-ply interfaces.

\section{Introduction}

Fiber reinforced laminated composites are attractive for many applications, especially in the aerospace industry where high mechanical performance under extreme loading with low density are desired. Despite their general outstanding performance, such composites are wellknown to be vulnerable to microscopic damage that accumulates under mechanical and thermal loading [1]. Although the failure behavior in laminated structures has been carefully studied, the mechanisms are difficult to predict accurately since they depend on many geometrical and structural properties, such as component geometry, loading conditions, stacking sequence and ply thickness [2-3]. Spread-tow thin-ply prepreg, herein after called "thinpreg", was introduced by Kawabee et al. [4-8], focuses on stable and gentle opening of dry tows so that flat fiber plies can be produced and subsequently pre-impregnated with a resin, as commonly done for conventional thickness prepregs. This technique allows the production of ultra-thin prepreg (up to $7 \times$ thinner than traditional prepreg) while suppressing issues associated with fiber arrangement and ply uniformity. Thinpreg laminates have several considerable advantages in terms of design and mechanical performance. For instance, the possibility of meeting design constrains with no 
change in laminate thickness or the use of smaller mismatch angles which has been shown to improve the interfacial fracture resistance. In terms of mechanical performance, it has been shown that thin-ply laminated composites can suppress microcracking, delamination and splitting damage [9-14]. This strengthening effect which inhibits crack growth in off axis plies within a laminate is a consequence of the so-called "in-i ffect", which is characterized by an increase in transverse and shear strengths when a ply is constrained by plies with different fibre orientations in a laminate [9]. In general, thin-ply composites exhibit enhanced unnotched strength, compressive notched strength, better resistance to fatigue and, if designed to trigger specific damage mechanisms, enhanced tensile notched strength [9-14]. However, the use of thinpreg presents a major problem as it requires a larger number of assembly steps to reach a desired laminate thickness, with the laminate then giving a larger number of ply interfaces. The interlaminar region at each ply interface is comprised of pure (un-reinforced) resin making it susceptible to interlaminar crack propagation and delamination, limiting the lifetime of the composite part [14]. From the perspective of preventing early delamination, modification of the interlaminar region in laminated composites has remained an active area of research for decades and includes technologies such as stitching, z-pinning and 3D weaving [15-22]. Thus, a drawback to thin-ply laminates is the increased number of relatively weak interlaminar regions, which we address here via nanostructure reinforcement.

In the past two decades, the use of nanomaterials as fillers and reinforcement in composites has been shown to be a viable technique to increase the interlaminar toughness and strength without compromising the integrity of laminated composites [23-26]. Recently, the ability to grow highly aligned arrays of densely packed CNTs offers possibility of local reinforcement, due to the high mechanical properties of CNTs (e.g., Young's modulus and strength exceeding 
aerospace-grade carbon fibers $[18,27])$ and developments in the fabrication and processing [28]. Garcia et al. [29] introduced a hierarchical architecture where A-CNTs are placed strategically between consecutive laminae/plies to reinforce the resin rich interlaminar region. This architecture was originally developed based on fracture mechanics work that showed a strong scale effect between toughness and nanoscale fibers reinforcing cracks (Mode I analysis) [30]. In-plane laminate properties were also investigated for laminates where all ply interfaces are reinforced with aligned CNTs [30-32]. The most important finding is that, as hypothesized, the laminate-level strengths are increased and damage propagation is delayed due to the presence of a stronger and tougher interface [30-32]. In that work, in-plane strengths were improved broadly and significantly: the critical bearing strength, the ultimate open-hole compression strength, and the L-shape laminate breaking energy of the nanostitched samples were increased by $30 \%, 14 \%$ and $40 \%$, respectively, compared to the unreinforced samples [31].

In this study, A-CNT nanostitching is employed for the first time to reinforce the interlaminar region of thin-ply composite laminates. Nanostitched Thin, and an effective standard thickness (herein after called 'Thick') version of a quasi-isotropic (QI) symmetric laminate are fabricated and tested (see Fig. 1) in short beam shear (SBS) to focus on interlaminar failure. The effect of nanostitching thinpreg laminates is visualized using Synchrotron Radiation Computed Tomography (SRCT) which allows the non-destructive visualization and comparison of internal damage extent of post mortem specimens. Damage trajectories, and differences between the four tested laminate configurations, is further analyzed by finite element simulations of progressive damage.

\section{Methods}


In the following sections, fabrication of the laminates is presented, including the A-CNT synthesis and transfer process, followed by the detailed experimental procedure for static SBS testing, characterization of post mortem samples, and detailed description of the finite element progressive damage modeling.

\subsection{Materials and laminates fabrication}

Vertically aligned CNTs (A-CNTs) were grown in a tube furnace (Lindberg/Blue M) by chemical vapor deposition (CVD) at atmospheric pressure following procedures previously documented [28]. The A-CNT forests have an areal density of $\sim 1$ vol\% corresponding to $10^{9}$ $10^{10} \mathrm{CNTs}$ per $\mathrm{cm}^{2}$ and comprised of 3-5 walls and an outer diameter of $\sim 8 \mathrm{~nm}$. The A-CNT forests are nominally $20 \mu \mathrm{m}$ in length with some variability $(\sim \pm 5 \mu \mathrm{m})$ in height with extremes of $15 \mu \mathrm{m}$ and $25 \mu \mathrm{m}$ noted. The A-CNTs were initrouuced to the interlaminar region by transferring them to the surface of the composite prepreg plies, utilizing the tack of the prepreg at room temperature. A unidirectional aerospace-grade carbon fiber and epoxy thinpreg tape (TohoTenax HTS40/Q1112, $54 \mu \mathrm{m}$ ply thickness) was used for the laminates fabrication. Two laminate types, Thin and Thick, were manufactured, with and without nanostitch, giving four laminate configurations in total. Thin consists of 48 thinpreg plies stacked in a quasi-isotropic (QI) symmetric layup $\left([0 / 90 / \pm 45]_{6}\right)_{\mathrm{s}}$ and Thick is an effective 16 ply $\left(\left[0_{3} / 90_{3} / \pm 45_{3}\right]_{2}\right)_{\mathrm{s}}$ laminate fabricated by stacking 3 thinpreg plies (a ply block) with identical orientation to reach the equivalent standard ply thickness of $150 \mu \mathrm{m}$ (see Fig. 1). Local nanostitching at the center of the laminate was utilized to reduce r $~$ A-CNT material and fabrication steps, and focused on the center of the laminate for selective reinforcement based on reported modes of failure in the SBS ASTM standard [33]. A-CNT nanostitches were placed in th $\rightarrow$ iddle interfaces in the Thin 
laminate configuration, which is equivalent $\mathrm{t}$ I the Thick laminate configuration, as displayed in Figs. 1a and 1b. Effectiveness of the transfer process was $\sim 90 \%$ by area. The $30 \mathrm{~cm} \times 30 \mathrm{~cm}$ laminated plates were wrapped in appropriate materials and cured under vacuum in an autoclave following the industry process specifications ( 1 bar of total pressure at $1.5^{\circ} / \mathrm{min}$ to $90{ }^{\circ} \mathrm{C}$, hold for $30 \mathrm{~min}$ and followed by $90 \mathrm{~min}$ at $120{ }^{\circ} \mathrm{C}$ at 7.9 of total pressure, cool at $3{ }^{\circ} \mathrm{C} / \mathrm{min}$ to $60{ }^{\circ} \mathrm{C}$ and vent pressure, let cool to room temperature). Baseline and nanostitched specimens are taken from the same plate. Once the laminates were cured, specimens were cut to size and prepared for tests. Specimen dimensions and test specifics are provided below.

\section{Thick nanostitched}

QI symmetric laminate $\left[\left(0_{3} / 90_{3} / \pm 45_{3}\right)_{2}\right]_{\mathrm{s}}$

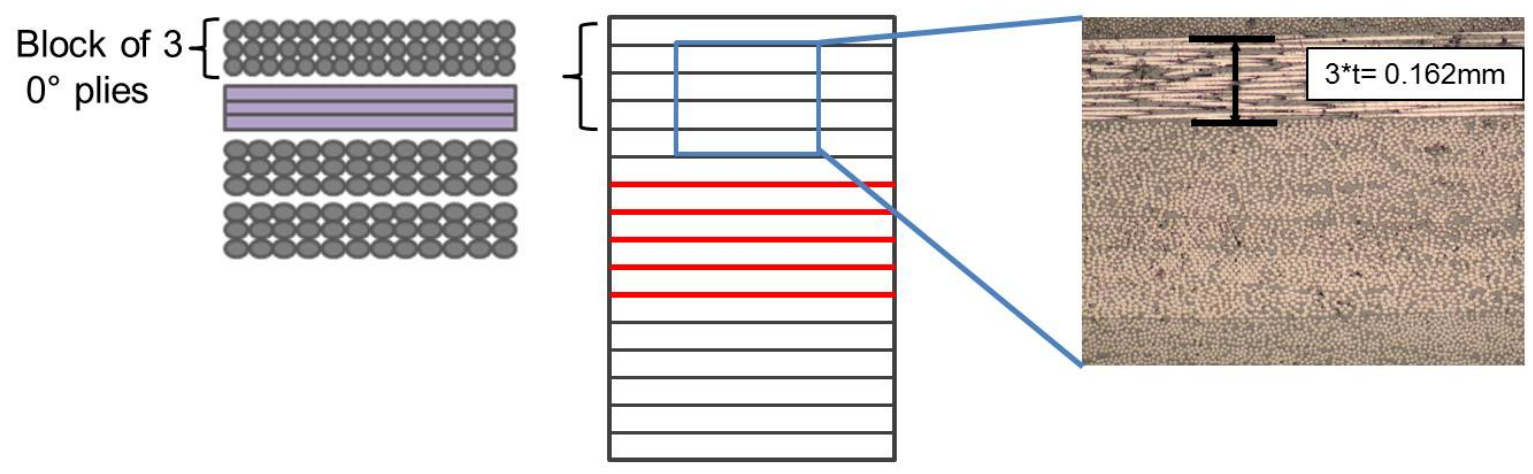

Thin nanostitched

QI symmetric laminate $\left[(0 / 90 / \pm 45)_{6}\right]_{s}$

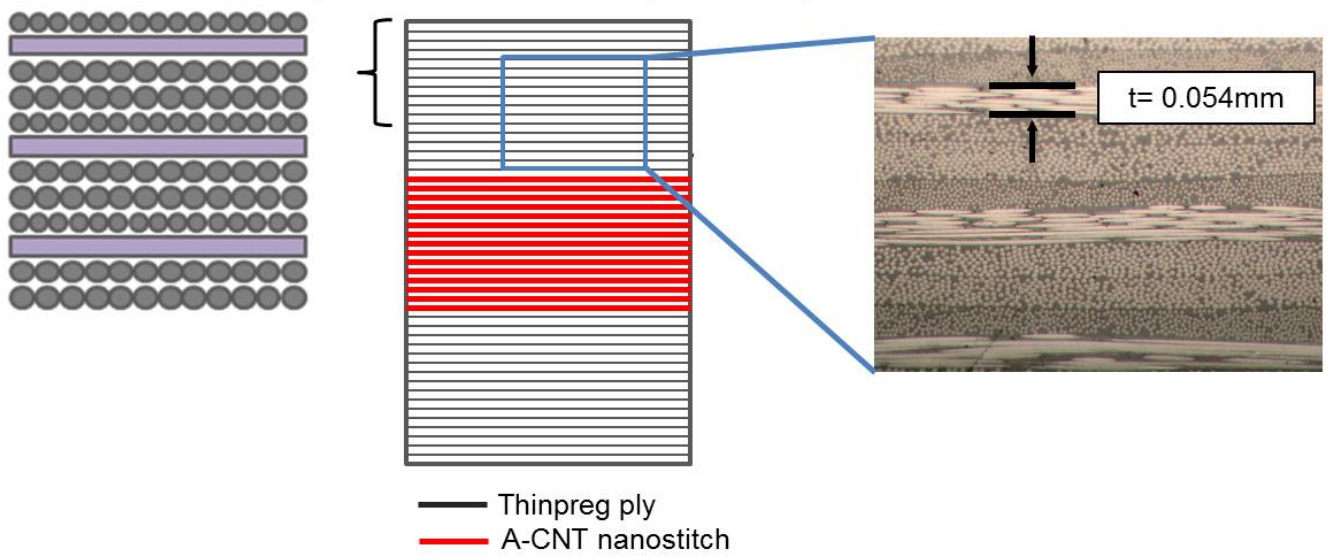


Fig 1: Thick and Thin laminate configurations: (top) Illustration of Thick laminate consisting of the stacking nsecutive thinpreg plies (black lines) to create an effective standard thickness laminate. $\mathrm{Tr}$ idplane interfaces are nanostitched with A-CNTs (red) and a representative optical micrograph of Thick cross-section appears at right. (bottom) Illustration of Thin laminate showing th $\longrightarrow$ iidplane nanostitched interfaces (red) and a representative optical micrograph appears at right. In both cases the laminate layup is quasi-isotropic (QI).

\subsection{Short beam shear mechanical testing}

The laminates were cut into test coupons with dimension of $5.2 \mathrm{~mm} \times 15.6 \mathrm{~mm} \times 2.6 \mathrm{~mm}$ for the width, length and thickness, respectively. The specimens were subsequently manually g d and polished on the edges to remove defects introduced by the cutting process, as recommended by ASTM D2344. At lea: Jecimens of each configuration (Thick, Thick nanositch, Thin, and Thin nanostitch) were tested under the static short beam shear configuration (ASTM D2344) [33]. The samples were loaded in a 3-point bending testing setup with a span of $10.5 \mathrm{~mm}$ and under a $5 \mathrm{~mm} / \mathrm{s}$ loading rate. The load-displacement curves were recorded during testing until catastrophic failure, and interlaminar shear strength (ILSS) in SBS, $\sigma_{S B S}$, was calculated according to eq. (1):

$$
\sigma_{S B S}=0.75 \times \frac{P_{\max }}{w \times t}
$$

where $P_{\max }$ is the maximum load and $w$ and $t$ are the width and the thickness of the specimen, respectively. 
2.3 Transfer assessment and morphology of the interlaminar region

Since the reinforcing effect is expected to be a consequence of the presence of the A-CNTs at the interfaces, assessment of the morphology of the interlaminar region is particularly important. Scanning electron microscopy (Zeiss, Ultra Plus) was used to assess the quality of the CNT nanostitching transfer and measure the interlaminar thickness. At least 20 interfaces were observed and measured for each laminate configuration. The average interlaminar thickness for baseline Thin and Thick was found to be $\sim 4 \mu \mathrm{m}$. The addition of A-CNT nanostitching (20 $\mu \mathrm{m}$ A-CNTs forest) to the interlaminar region increases the interlaminar thickness by $\sim 50 \%$ as shown in Table 1. This was not observed in prior nanostitching work [30, 32, 34], and further investigations should be done to ensure minimum increase of the interlaminar region thickness. Additionally, it should be noted that the overall laminate thickness was not significantly increased since only the middle planes of the laminate are nanostitched, thereby retaining the overall laminate microfiber volume fraction across all laminate configurations. Fig. 2 shows high resolution cross-sectional images of a typical nanostitched interface in Thin baseline and Thin nanostitched samples. The micrograph reveals that the A-CNTs were effectively transferred onto the prepreg, properly filling of the interlaminar resin rich area. Furthermore, the A-CNTs effectively bridge the two plies and inte tate through the fibers. This morphology is essential to the toughening mechanism involved in nanostitching, which often include CNTs pullout and bridging $[32,34]$. Similar features are observed in nanostitched interfaces of Thick baseline specimens (see Fig. S1). 
Table 1: Laminate and interlaminar thicknesses.

\begin{tabular}{lcc}
\hline Laminate configuration & Laminate thickness $(\mathbf{m m})$ & Interlaminar thickness $(\boldsymbol{\mu m})$ \\
\hline Thick baseline & $2.58 \pm 0.02$ & $3.5 \pm 1.3$ \\
Thick nanostitched & $2.58 \pm 0.01$ & $7.9 \pm 1.8$ \\
Thin baseline & $2.60 \pm 0.01$ & $4.2 \pm 1.1$ \\
Thin nanostitched & $2.62 \pm 0.01$ & $7.8 \pm 1.4$ \\
\hline
\end{tabular}

a)

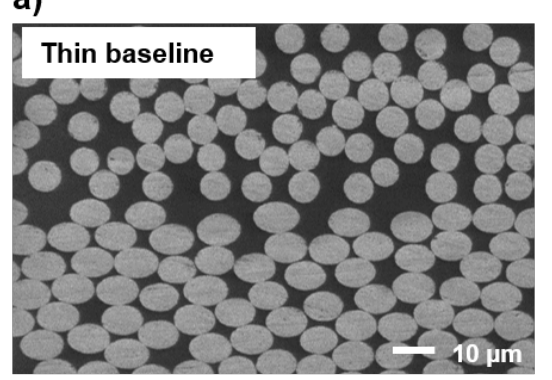

b)

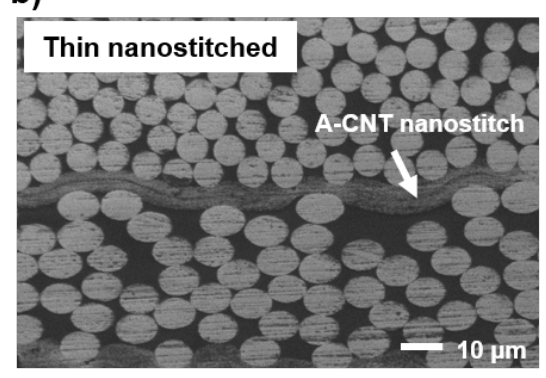

c)

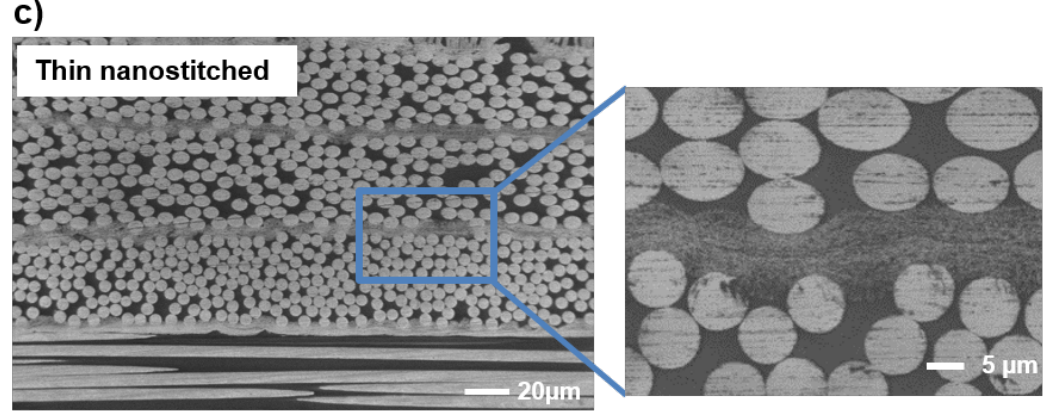

Fig. 2. Representative scanning electron micrographs of ply interfaces in baseline and nanostitched specimens: (a) a 90/45 Thin baseline laminate, (b) an A-CNT reinforced 90/45 interface with aligned CNTs visible as light grey area, (c) Lower magnification of A-CNT 
reinforced interface for [45/90/0] interfaces showing the A-CNTs bridging the layers of microfiber plies. In the inset, a higher magnification of the nanostitched 45/90 interface from (c).

\subsection{Synchrotron Radiation Computed Tomography (SRCT)}

SRCT experiments were carried out at the ID 19 beamline at the European Synchrotron

Facility (ESRF) in Grenoble, France Thick and Thin laminates (baseline and nanostitched) previously tested under short beam shear configuration were scanned ex situ using a $20 \mathrm{keV} \mathrm{X-}$

energy beam with projections captured $\mathrm{a}^{\text {t }} \mathrm{a} \sim 0.7 \mu \mathrm{m}$ isotropic voxel resolution $(1 \mathrm{~mm} \times 1$ $\mathrm{mm}$ field of view) and $50 \mathrm{~ms}$ exposure. Furtier analysis and segmentation of the 3D volumes were performed using Avizo (FEI) commercial software version 9.3.

\subsection{Progressive damage modeling}

Simulation of the SBS test was performed to better rstand the consequences of reinforcing the interfaces with A-CNTs. The simulation of damage in composite laminates requires the use of models that can capture both intralaminar (matrix cracking, fiber fracture) and interlaminar (delamination) damage. In this work, intralaminar damage is simulated using the continuum damage model proposed by Maimí et al. [35-37] using the cohesive zone model implemented in ABAQUS [38]. For nanostitched interfaces, this is a simplification since these models were not developed to account for the inelastic deformation and fracture of nanoreinforced interfaces. The model is composed of: (i) two lower supports composed of C3D8r elastic elements, (ii) a loading nose composed of C3D8r elastic elements, and (iii) the laminate. One user material C3D8r finite element per ply is used to simulate intralaminar damage and the plies are connected by $0.01 \mathrm{~mm}$ thick $\mathrm{COH} 3 \mathrm{D} 8$ cohesive elements shown in Fig. S2 
(Supplementary Information). The supports and loading nose are also simulated to avoid unrealistic damage development on the outer layers and because their dimensions are not negligible compared to the dimensions of the specimens. A mesh of $0.25 \mathrm{~mm} \times 0.25 \mathrm{~mm} \times \mathrm{t} \mathrm{mm}$ (where $\mathrm{t}$ is the ply thickness: $54 \mu \mathrm{m}$ for the Thin configurations, and $162 \mu \mathrm{m}$ for the Thick configurations) is used for the ply elements and $0.25 \mathrm{~mm} \times 0.25 \mathrm{~mm} \times 0.01 \mathrm{~mm}$ for the cohesive elements. The mesh and boundary conditions used are shown in Fig. S2.

Since most of the material properties needed to simulate intralaminar and interlaminar damage are unknown for the HTS40/Q-1112 carbon/epoxy material system, approximations were made based on existent work. The material properties used are not relevant since the goal is not to get accurate predictions of the load displacement curve and ILSS but rather to better understand the differences in damage propagation of the Thick baseline, Thin baseline and Thin nanostitched configurations. In the simulations of the unreinforced samples, the fracture toughness of the elements in every interface is the same. However, ir $\sim$ e of nanostitched, previous studies link the improvement in ILSS [30,31] to a substantial increase of the interlaminar toughness. Hence, in the present model, interlaminar elements representing nanostitched interfaces are give sher fracture toughness which itute is computed via iterative simulations based on Hexcel AS4/8552 prepreg as a proxy materials. The cohesive stresses are calculated using two engineering solutions proposed by Turon and co-authors [39-40] to enable a better representation of the softening behaviou $\checkmark$ he vicinity of the crack tip and to avoid a common erroneous calculation of the of the energy dissipation. Detailed model, procedure and results are presented in Figure S3 (Supplementary information) and associated discussion. 


\section{Results and Discussion}

In this seetion, the interlaminar shear strength of the laminates is diseussed and the effeets of thin-ply laminate technologies and 1 titehing are further investigated by SRCT and numerieal progressive damage modeling.

The four specimen configurations were tested via SBS to measure the ILSS. This configuration restricts the shear-dominated loading to a limited zone where relatively high interlaminar shear stresses develop, causing failure in an out-of-plane shear dominated mode. Table 2 summarizes the ILSS results for th $\square$ minate configurations, and representative load displacement curves are shown in Fig. 3. Typical modes of failure observed include delamination at the center of the laminate cross section and at the free edges, but may also include fiber breaks and compressive damage at the load introduction points at the surface of the specimen, as identified

referred in [33]. Within the Thick specimens, no statistically significant change was observed after nanostitching. This is in contrast to prior work that has shown an $6.5 \%$ increase for standard thickness specimens of a different UD prepreg system [32], although more recent work has also shown a statistically insignificant increase in strength in static SBS for another UD prepreg system, but fatigue life in SBS increased significantly [41]. It seems that small or negligible increases in strength are revealed in SBS testing across the two standard thickness systems studied so far, equivalent to the blocked ply Thick configuration herein. As noted earlier, future work will pursue optimizing the A-CNT forest height to maintain the interlaminar region thickness. The comparison between Thin and Thick laminates shows an increase of $10 \%$ in the ILSS of Thin baseline over the Thick baseline samples, and an additional $5 \%$ increase in the Thin nanostitched over the baseline Thick samples. These results support our hypothesis that nanostitching can delay ultimate failure, in particular in thinpreg laminates. In Fig. 3, post 
mortem SEM observations of specimen cross sections reveal extensive CNT pullout and local debonding of the CNT layer at the interlaminar region. This is expected since it was also reported in previous work on nanostitching [30-32] that delayed delaminatior $\square$ orrelated to an increase in interlaminar fracture toughness, i.e., reinforcement provided by the addition of high aspect ratio nanofibers (A-CNTs here).

To understand the mechanisms involved in the observed synergy between thin-ply technologies and A-CNT nanostitching, post mortem assessment of the damage type and extent is undertaken via computed tomography. Imaging a full volume in $3 \mathrm{D}$ was possible using $\mathrm{SRCT}$, which allowed the visualization of internal damage with sufficient resolution to distinguish delamination, matrix cracks and fiber breaks.

\section{Table2}

Interlaminar Shear Strength (ILSS) via SBS for baseline and nanostitched Thick and Thin laminates. Only statistically significant changes are noted.

\begin{tabular}{lll}
\hline Laminate type & ILSS (MPa) & Change (\% vs. Thick baseline) \\
\hline Thick baseline & $69.9 \pm 2.4$ & \\
Thick nanostitched & $69.8 \pm 1.3$ & \\
Thin baseline & $76.9 \pm 1.1$ & $+10.1 \%$ \\
Thin nanostitched & $80.6 \pm 0.6$ & $+15.3 \%$ \\
\hline
\end{tabular}




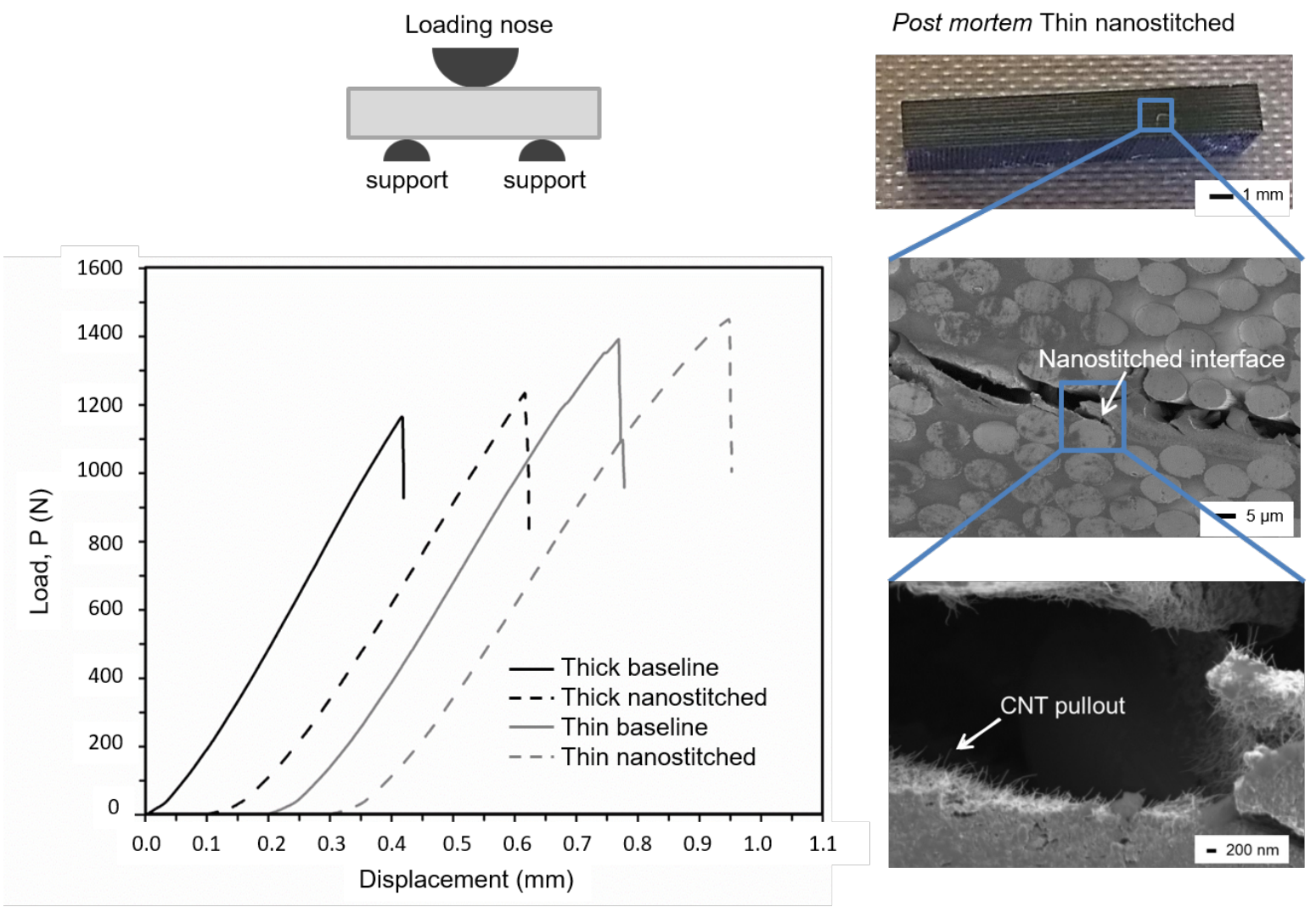

Fig. 3: Short beam shear strength (SBS) testing results: (left) Representative SBS loaddeformation curves at median values for strength). For comparison, the curves were shifted in the $\mathrm{x}$ axis; (right) Micrographs of a post mortem Thin nanostitched interface showing a crack micrometer through the nanostitch-ply interface and mieron-long CNT pullout from the polymer.

Post mortem Thick (baseline), Thin and Thin nanostitched coupons were inspected by SRCT at $\sim 0.7 \mu \mathrm{m}$ vox. resolution, allowing microfiber breaks, delamination, and intralaminar matrix cracks to be easily observed. Since the effect of nanostitching was less pronounced in the Thick configuration, no SRCT analysis was performed on these samples. Damage, segmented in red for delamination and blue for matrix cracks are shown in Fig. 4. The segmented damage reveals that 
Thick and Thin baselines fail differently: Thick baseline contains extensive damage in the center of the specimen where shear stresses are highest in the SBS test, with large matrix cracks developing in the 45 plies, and in the vicinity of clear delamination planes. As expected, Thin baseline samples exhibit more localized damage than the baseline with delaminations at the $7^{\text {th }}$, $11^{\text {th }}$, and $29^{\text {th }}$ interfaces, with confined transverse matrix cracks in the $45^{\circ}$ plies. We note the asymmetry of matrix cracking density within the specimen thickness, i.e., more cracks are detected on the upper side of the specimen where the plies are under compression (near the loading nose and the laminate midplane),. Interestingly, the intralaminar cracks developed in the Thin baseline are arrested and remain constrained to the intra-laminar regions, as opposed to the Thick baseline which exhibits intralaminar damage extending through consecutive thin plies. This effect results to less extensive intralaminar damage at the laminate level that ean be here, and more generally in the extend work ?iscussed earlier, associated with higher strengths [42]. However, because the number of plies and interfaces is tripled in the case of thinpreg laminates, the number of delaminations increases concomitantly. For Thick baseline samples, the matrix crack extension which occurs through the laminate thickness, leads to stress relaxation, whereas in the Thin baseline, matrix cracks appear in individual thin plies and do not extend from ply to ply. Further increase of applied loading yields the increase of the matrix crack density within the lamina while the high stress field at the interlan region evolves into interlaminar damage, as seen in the high density of delamination zones in Fig.4. Thin nanostitched samples exhibit similar intralaminar damage as Thin baselines. Although delaminations are still visible, the number of damaged interfaces is significantly reduced, and in the region that is reinforced with A-CNTs delaminations are fully suppressed. The fact that no delamination is observed in the CNT area indicates a positive reinforcing effect. Although nanostitching yields only a $5 \%$ 
increase in the SBS ILSS, SRCT visualization demonstrates that delamination is clearly mitigated by nanostitching.

Results of progressive damage modeling supports the SRCT observations that the reinforcing effect of nanostitching for the Thin configuration has the clear effect of mitigating delaminations, and to a lesser extent, matrix cracking in the middle region of the laminate thickness (see Fig. 4). Damage accumulation at three points along the linear load-deflection curve are reported for the three configurations in Fig. 5. Note that matrix damage extent shown in Fig. 4 is different from the damage extent in Fig. 5, as the former (Fig. 4) looks at damage at the specimen crosssectional surface, whereas the latter (Fig. 5) provides an integrated projection of all damage through the specimen width. The integrated view in Fig. 5 allows us to compare the damage propagation for the different laminate configurations. There is no damage at $80 \%$ of $P_{\max }$ apart from that due to high compressive and shear stresses under the loading nose, but just before failure at $100 \%$ of $P_{\max }$, the Thick and Thin baseline laminates show several interlaminar cracks and partial damage at the interlaminar region is already observed in Thin configuration (green lines), although catastrophic failure is not yet reached. The Thin nanostitched has suppressed interlaminar damage extent in the A-CNT region as is expected given the increase in interlaminar fracture toughness of $+15 \%$ employed in the modeling of the cohesive elements. This follows our hypothesis that the increased number of interfaces is ${ }_{\text {in }}$ baseline are prone to early failure (vs. the Thick baseline) as shown by the multiple damaged elements reported in the model. After failure (load drops to $50 \%$ of $P_{\max }$ ), damage extent is increased in all configurations, with multiple interlaminar cracks and damage in the Thick baseline and Thin baseline, that are absent in Thin nanostitched configuration. 


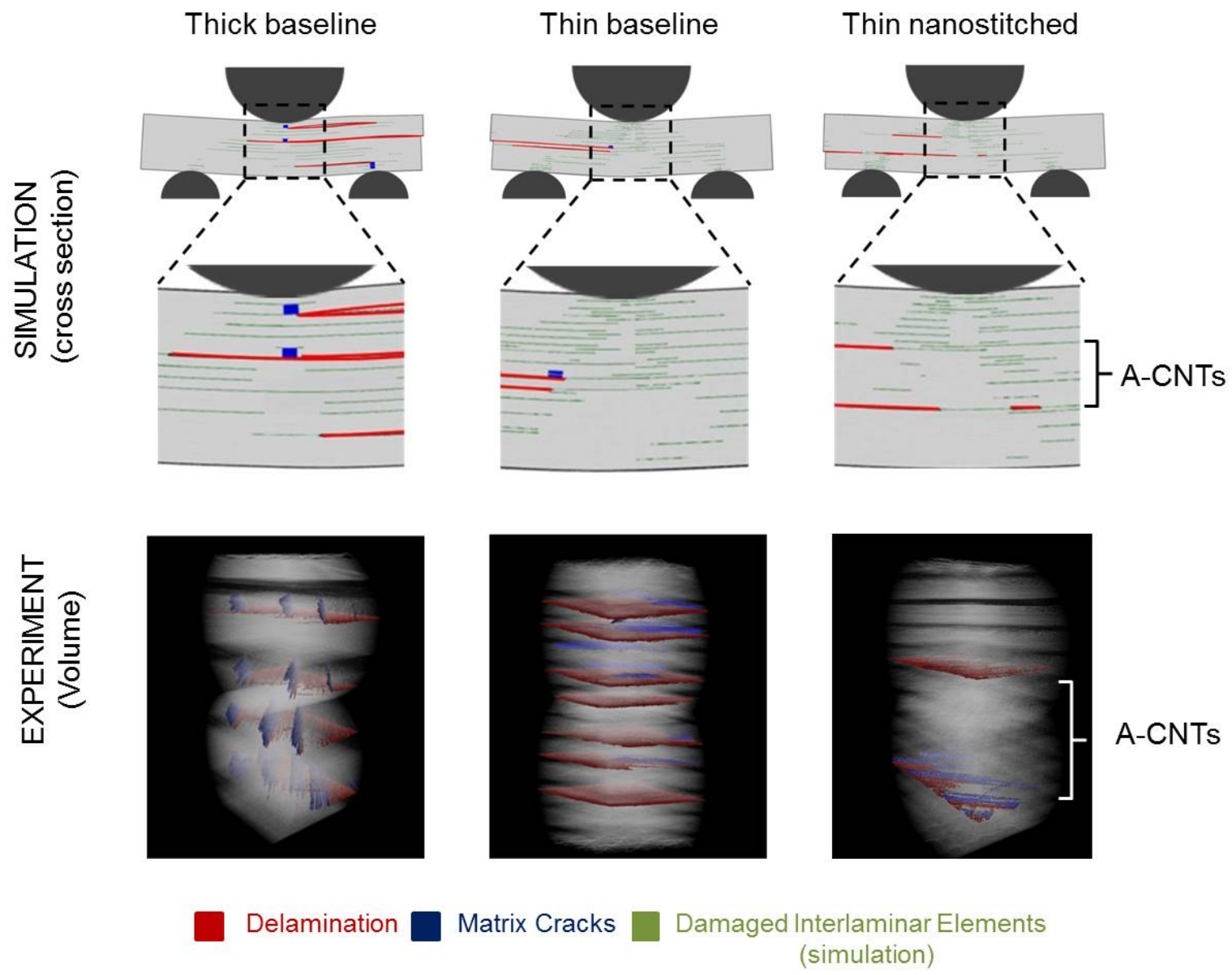

Fig. 4: Model predictions and 3D SRCT inspection of damage in post mortem coupons. (top) Predicted damage at the cross-section surface in Thick baseline, Thin baseline and Thin nanostitched (with close up on predicted damages observed under the loading nose), and (bottom) Respective SRCT 3D visualization of damage formation after experimental SBS failure. Colors represent: delamination (red), damaged interlaminar elements (green), and intralaminar matrix cracks (blue). Note that fiber breaks exist in the images, concentrated at the contact zone with the loading zone but are not shown/colored. Qualitatively, no observable differences are observed in the density or distribution of fiber breaks across any of the specimen configurations. 


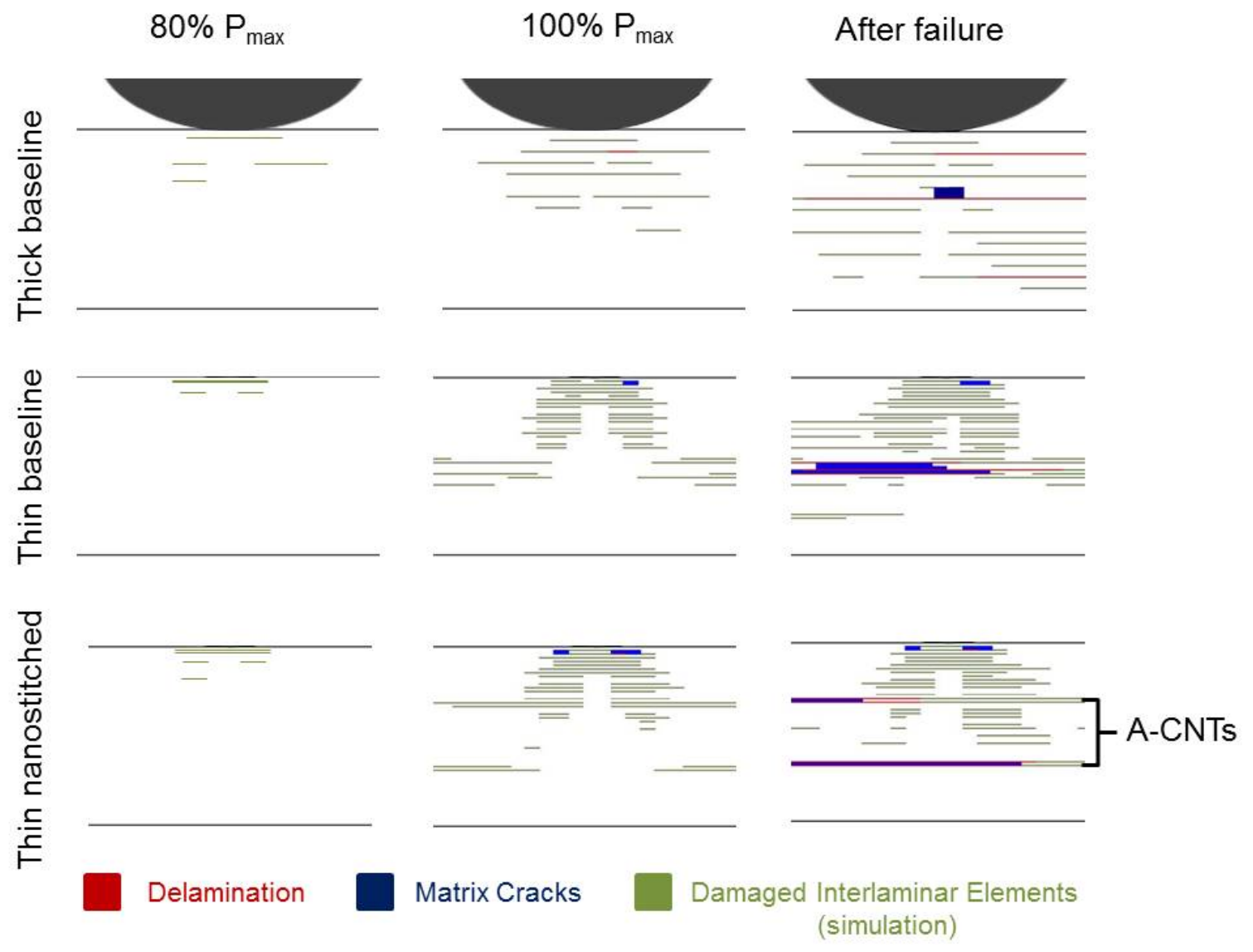

Fig. 5: Prediction of damage formation under SBS loading, shown as a projection of all internal (volumetric) damage integrated through the specimen width, for Thick baseline, Thin baseline and Thin nanostitched laminates at locations at $80 \% P_{\max }$, immediately before failure $(100 \%$ $\left.P_{\max }\right)$ and after failure $\left(50 \%\right.$ drop in load from $\left.P_{\max }\right)$. All specimen show matrix cracking (blue), interfacial delamination (red) and damaged interfacial elements (green). Only the region under the loading nose is shown. Note that fiber breaks exist, concentrated at the contact zone with the loading zone but are not shown/colored.

\section{Conclusions and Recommendations}


We have reported the successful reinforcement of thin-ply laminated advanced composites with aligned carbon nanotube (A-CNT) nanostitching and compared the mechanical performance in shear strength testing for four laminate configurations. The A-CNTs were $\operatorname{trar} \longrightarrow \mathrm{d}$ a transfer printing technique without affecting the overall laminate thickness, but did $\square$ nce a $50 \%$ increase in the interlaminar region thickness. Testing in short beam shear loading reveals an ILSS improvement of $10 \%$ in Thin and an adc al $5 \%$ increase after nanostitching, over Thick laminates. SRCT observations reveal the suppression of large matrix dominated cracks in Thin laminates, and the suppression of delamination in the nanostitched zone, vs. the baseling Thick (standard thickness) laminates. These findings were substantiated by progressive damage model -ling results utilizing $\frac{1-150}{\mathrm{~N}+150}$ A-CNTs. This work pioneers the investigation of synergies from two promising composite laminate technologies and gives fundamental insights into the damage progression and how it is affected by each technology separately, and together. Further investigation on A-CNT height will offer the possibility to maximize these effects for incre $\square 3 S$ strength, and future work will undertake to develop both full predictive damage models utilizing cohesive zone laws measured for the A-CNT nanostitched laminates, as well as in $\square$ ite other loading configurations such as compression-after-impact $(\mathrm{CAI})$ and open hole compression $(\mathrm{OHC})$ that are known to be strongly influenced by delaminations, a mode of failure thin-ply laminates are particularly susceptible to given the increased number of ply interfaces.

Acknowledgments 
This work was supported by National Funds through FCT - Fundação para Ciência e a Tecnologia in the scope of project MITP-TB/PFM/0005/2013, and by Airbus, Embraer, Lockheed Martin, Saab AB, Hexcel, Saertex, TohoTenax, and ANSYS through MIT's NanoEngineered Composite aerospace STructures (NECST) Consortium. The authors thank Mike Kinsella (TohoTenax) for helpful technical discussions. This work made use of facilities supported in part by the U. S. Army Research Laboratory and the U. S. Army Research Office through the Institute for Soldier Nanotechnologies, under contract number W911NF-13-D-0001, the facilities at the U.S. Army Natick Solider R, D \& E Center (NSRDEC), and was carried out in part through the use of MIT's Microsystems Technology Laboratories (MTL). The SRCT experiments were performed on beamline ID 19 at the European Synchrotron Radiation Facility (ESRF), Grenoble, France. We are grateful to Lukas Helfen and Elodie Boller at the ESRF for providing assistance in using beamline ID 19. This work was performed in part at the Center for Nanoscale Systems (CNS), a member of the National Nanotechnology Coordinated Infrastructure Network (NNCI), which is supported by the National Science Foundation under NSF award no. 1541959. CNS is part of Harvard University. This material is based upon work supported by the National Science Foundation Graduate Research Fellowship Program under Grant No. 1122374. Any opinions, findings, and conclusions or recommendations expressed in this material are those of the author(s) and do not necessarily reflect the views of the National Science Foundation. The authors thank Dr. Itai Stein, and the entire necstlab at MIT and lab members at $\mu$-VIS X-Ray Imaging Center at University of Southampton for valuable discussion and input. The authors thank TohoTenax for materials donation of the thin-ply prepreg material.

\section{References}


1. G. Han, Z. Guan, Z. Ji, S. Du, Initial damage induced by thermal residual stress and microscopic failure analysis of carbon-fiber reinforced composite under shear loading, Compos. Inter. (2015) 22 315-329.

2. N.J. Pagano, R.B, The influence of stacking sequence on laminate strength, J. Compos. Mater. 1 (1971) 50-57.

3. C.T. Herakovich, Influence of layer thickness on the strength of angle-ply laminates, J. Compos. Mater. 16 (1982) 216-227.

4. K. Kawabe, S. Tomoda, Multi-filament split-yarn sheet and method and device for the manufacture thereof. Patent no. 6032342, USA, 2000.

5. K. Kawabe, S. Tomoda, Method of producing a spread multi-filament bundle and an apparatus used in the same. Patent no. 7832068, USA, 2010.

6. K. Kawabe, S. Tomoda, T.A. Matsuo, A pneumatic process for spreading reinforcing fiber tow. In: Proceedings of the 42nd International SAMPE USA, Anaheim, CA, USA, 4-8 May $1997,65-76$.

7. H. Sasayama, K. Kawabe K, S. Tomoda, I. Ohsawa, K. Kageyama, N. Ogata, Effect of lamina thickness on first ply failure in multidirectionally laminated composites. In: Proceedings of the 8th Japan International SAMPE, Tokyo Big Sight, Japan, 18-21 November 2003, pp.18-21.

8. K. Kawabe, H. Sasayama, S. Tomoda, New carbon fiber tow-spread technology and applications to advanced composite materials. SAMPE J. 45 (2009) 6-17. 
9. R. Amacher, J. Cugnoni, J. Botsis, L. Sorensen, W. Smith, C. Dransfeld, Thin ply composites: Experimental characterization and modeling of size-effects, Compos. Sci. Technol. 132 (2014) 101-121.

10. Y. Sihn, R. Kim, K. Kawabe, S Tsai, Experimental studies of thin-ply laminated composites, Compos. Sci. Technol. 67 (2007) 996-1008.

11. T. Yokozeki, Y. Aoki, T. Ogasawara, Experimental characterization of strength and damage resistance properties of thin-ply carbon fiber/toughened epoxy laminates, Compos. Struct., $82(2008) 382-389$

12. C. Furtado, A. Arteiro, G. Catalanotti, J. Xavier, P.P. Camanho, Selective ply-level hybridisation for improved notched response of composite laminates. Compos. Struct., 145 (2016) $1451-14$.

13. A. Arteiro, G. Catalanotti, J. Xavier, and P.P. Camanho, Notched response of non-crimp fabric thin-ply laminates. Compos. Sci.Technol. 79 (2008) 79:97

14. A. Faggiani , B. G. Falzon, Predicting low-velocity impact damage on a stiffened composite panel, Compos. Part A 41 (2010) 737-749.

15. L. Tong, A. P. Mouritz, M. K. Bannister, L. Tong, A. P. Mouritz, M. K. Bannister, 3D Fibre Reinforced Polymer Composites, Elsevier, 2002.

16. K. A. Dransfield, L. K. Jain, Y.-W. Mai, On the effects of stitching in CFRPs-I. mode I delamination toughness, Compos. Sci. Technol. 58 (1998) 815-827.

17. A. P. Mouritz, K. H. Leong, I. Herszberg, A review of the effect of stitching on the in-plane mechanical properties of fibre-reinforced polymer composites, Compos. Part A 28 (1997) $28979-991$. 
18. L. Gorbatikh, B.L. Wardle ,S.V. Lomov, Hierarchical Lightweight Materials for Structural Applications, MRS Bull. 41 (2016) 672-677.

19. F. Larsson, Damage tolerance of a stitched carbon/epoxy laminate, Compos. Part A 28 (1997) 923-934.

20. I. K. Partridge D. D. R. Cartié, Delamination resistant laminates by Z-Fiber pinning: Part I manufacture and fracture performance, Compos. Part A 36 (2005) 55-64.

21. K. T. Tan, A. Yoshimura, N. Watanabe, Y. Iwahori, T. Ishikawa, Effect of stitch density and stitch thread thickness on damage progression and failure characteristics of stitched composites under out-of-plane loading, Compos. Sci. Technol. 74 (2013) 194-204.

22. N. A. Siddiqui, R. S. C. Woo, J.-K. Kim, C. C. K. Leung, A. Munir, Mode I interlaminar fracture behavior and mechanical properties of CFRPs with nanoclay-filled epoxy matrix, Compos. Part A. 38 (2007) 449-460.

23. T. Yokozeki, Y. Iwahori, S. Ishiwata, K. Enomoto, Mechanical properties of CFRP laminates manufactured from unidirectional prepregs using CNT-dispersed epoxy, Compos. Part A. $3820072121-2130$.

24. B. Fiedler, F. H. Gojny, M. H. G. Wichmann, M. C. M. Nolte, K. Schulte, Fundamental aspects of nano-reinforced composites," Compos. Sci. and Tech., 66 (2006) 3115-3125.

25. R.J. Sager, P.J. Klein, D.C. Lagoudas, Q. Zhang, J. Liu, L. Dai, J.W Baur, Effect of carbon nanotubes on the interfacial shear strength of T650 carbon fiber in an epoxy matrix, Compos. Sci. Technol. 69 (2009) 898-904.

26. P.R. Thakre, D.C. Lagoudas, J.C. Riddick, T.S. Gates, S.J. V. Frankland, J.G. Ratcliffe, J. Zhu, E.V. Barrera, Investigation of the effect of single wall carbon nanotubes on 
interlaminar fracture toughness of woven carbon fiber-epoxy composites, J. Compos. Mater. 45 (2011) 1091-1107.

27. M.F.L. de Volder, S.H. Tawfick, R.H. Baughman, A.J. Hart, Carbon Nanotubes: Present and Future Commercial Applications, Science 339 (2013) 535-539.

28. E.J. Garcia, B.L. Wardle, J. Hart, N. Yamamoto, A. Slocum, Fabrication and Multifunctional Properties of a Hybrid Laminate with Aligned Carbon Nanotubes Grown In Situ, Compos. Sci. Tech., 68 (2008) 2034-2041.

29. E.J. Garcia, B.L. Wardle, J. Hart, A. Slocum, Joining Prepreg Composite Interfaces with Aligned Carbon Nanotubes, Compos. Part A, 39 (2008) 1065-1070.

30. J. Blanco, E.J. Garcia, R. Guzmán de Villoria, B.L. Wardle, Limiting mechanisms in mode I interlaminar toughness of composites reinforced with aligned carbon nanotubes, J. Compos. Mater., 43 (2009) 825-842.

31. R. Guzmán de Villoria, P. Hallander, L. Ydrefors, P. Nordin, B. L. Wardle. In-plane strength enhancement of laminated composites via aligned carbon nanotube interlaminar reinforcement, Compos. Sci. Technol. 133 (2016), 33-39.

32. D. Lewis, B.L. Wardle, Interlaminar shear strength investigation of aligned carbon nanotube-reinforced prepreg composite interfaces, AIAA SciTech 2015, Kissimmee, Florida 5-9 January 2015.

33. ASTM D2344 "Standard test method for short-beam strength of polymer matrix composite materials and their laminates".

34. E. Kalfon-Cohen, J. Orr, P. Skatis, L. Li, E. Shuter, D.J Lewis, B. L. Wardle, Structureprocess-property study of aligned carbon nanotube reinforcement height on mnterlaminar 
morphology in woven carbon fiber pepreg laminates. AIAA SciTech 2016, San Diego, California 4-8 January 2016.

35. P. Maimí, P. P. Camanho, J. A. Mayugo, C. G. Dávila, A continuum damage model for composite laminates: Part I - Constitutive model, Mech. Mater., 39 (2007) 897-908.

36. P. Maimí, P. P. Camanho, J. A. Mayugo, and C. G. Dávila, A continuum damage model for composite laminates: Part II - Computational implementation and validation, Mech. Mater., 39 (2007) 909-919.

37. P. Maimí, "Modelización constitutiva y computacional del daño y la fractura de materiales compuestos," Universitat de Girona, 2007.

38. Dassault Systèmes, ABAQUS User's Manual. 2011.

39. A. Turon, P. P. Camanho, J. Costa, An engineering solution for mesh size effects in the simulation of delamination using cohesive zone models, Eng. Fract. Mech., 74 (2007) 16651682.

40. A. Turon, P. P. Camanho, J. Costa, J. Renart, Accurate simulation of delamination growth under mixed-mode loading using cohesive elements: Definition of interlaminar strengths and elastic stiffness,Compos. Struct. 92 (2010) 1857-1864.

41. X. Ni, E. Kalfon-Cohen, C. Furtado, R. Kopp, N.F. Fritz, A. Arteiro, G.A. Valdes, G.Bostnar, M.N. Mavrogordato, S.M. Spearing, P.P. Camanho, B.L. Wardle, Interlaminar reinforcement of carbon fiber composites using aligned carbon nanotubes, $21^{\text {st }}$ ICCM, X'an, China, August 20-25 2017 
42. H. Saito, H. Takeuchi, I. Kimpara, A study of crack suppression mechanism of thin-ply carbon-fiber-reinforced polymer laminate with mesoscopic numerical simulation, J. Compos. Mater. 48 (2014) 2085-2096. 


\section{Supplementary Information: SYNERGETIC EFFECTS OF ALIGNED CARBON NANOTUBE INTERLAMINAR REINFORCEMENT AND THIN PLIES IN COMPOSITE LAMINATES}

1. Inspection of Thick interlaminar regions

SEMs below show cross sections of Thick baseline and nanostitched samples, showing 3 consecutive plies with identical microfiber orientation forming ply blocks for the Thick configuration. The A-CNT nanostitch is seen at the interface between 3 consecutives plies and fills integrally the interlaminar region as observed for Thin samples. This is not surprising as Thick samples are manufactured with thinpreg and identical interfaces are expected.

a)

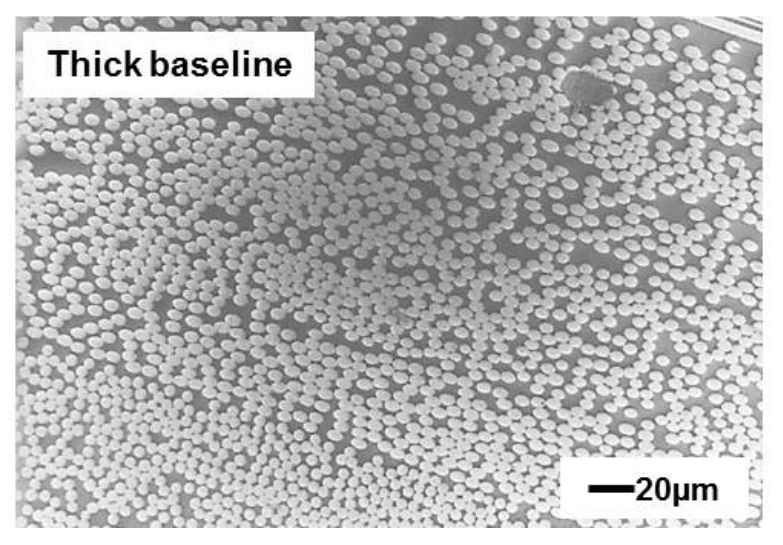

b)

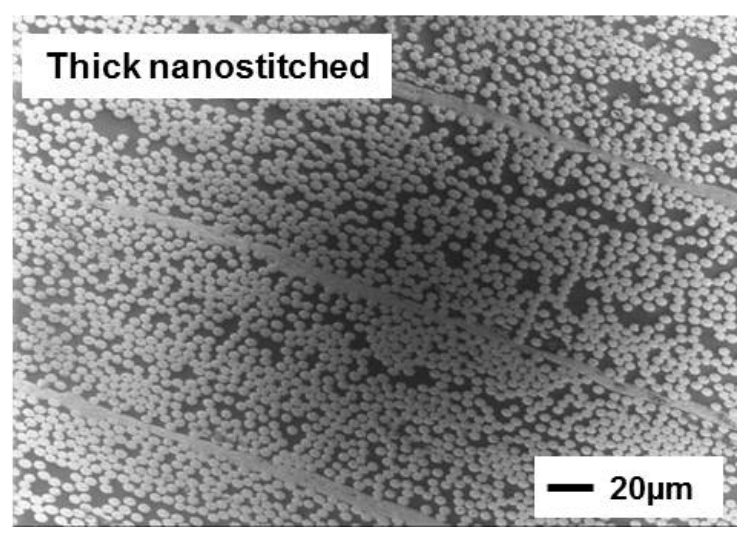

Figure S1: Scanning electron micrographs of Thick laminate cross sections: (a) Thick baseline, and (b) Thick nanostitched. 
2. Details of progressive damage finite element modeling

The model was developed to predict the onset and accumulation of intralaminar damage mechanisms (matrix cracking and fiber fracture) in laminated composites. The continuum damage model was defined in the framework of the thermodynamics of irreversible processes. Generally speaking, the formulation of the continuum damage models starts by the definition of a potential (the complementary free energy density) as a function of damage variables, which is the basis for establishing the relation between the stress and the strain tensors. More details on the continuum damage model can be found in refs [35-37].

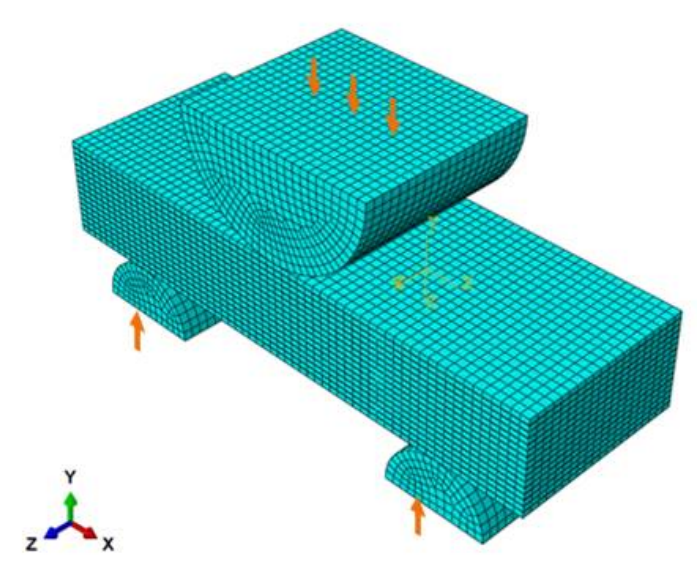

Fig. S1: Mesh and boundary condition used in the FEA model

Since most of the material properties needed to simulate intralaminar and interlaminar damage are unknown for the HTS40/Q-1112 carbon/epoxy material system at this point of the work, only a qualitative analysis was made for this material. The material properties used are not relevant since the goal is not to get accurate predictions of the load displacement curve and ILSS but rather to better understand the differences in damage propagation of the different material 
configurations. In the simulations of the unreinforced samples (Thick baseline and Thin baseline) the fracture toughness of the elements in every interface are the same. However, since the middle 15 interfaces are reinforced for the Thin nanostitched samples, the fracture toughness of the elements on those interfaces are increased. Since the toughening factor induced by the presence of the A-CNTs is not known, three enhancement factors were used: 5\%, 10\%, 15\% and 20\%. A summary of the simulations performed are shown in table S1.

\begin{tabular}{|c|c|c|c|c|c|c|}
\hline Reference & Layup & $\begin{array}{l}\text { Nanostitche } \\
\text { interfaces }\end{array}$ & & $\begin{array}{l}\text { Assumed } \\
\text { enhancemen } \\
\mathrm{t} \text { factor }\end{array}$ & $\begin{array}{l}\mathrm{G}_{\mathrm{Ic}} \\
{\left[\mathrm{kJ} / \mathrm{m}^{2}\right]}\end{array}$ & $\begin{array}{l}\mathrm{G}_{\mathrm{IIc}} \\
{\left[\mathrm{kJ} / \mathrm{m}^{2}\right.} \\
]\end{array}$ \\
\hline Thick-baseline & $\left(\left[0_{3} / 90_{3} / \pm 45_{3}\right]_{2}\right)_{\mathrm{s}}$ & None & & - & $\mathrm{G}_{\mathrm{Ic}}$ & $\mathrm{G}_{\text {IIc }}$ \\
\hline Thin baseline & $\left([0 / 90 / \pm 45]_{6}\right)_{\mathrm{s}}$ & None & & - & $\mathrm{G}_{\mathrm{Ic}}$ & $\mathrm{G}_{\mathrm{IIc}}$ \\
\hline Thin nanostitched 5\% & $\left([0 / 90 / \pm 45]_{6}\right)_{\mathrm{s}}$ & $\begin{array}{l}\text { Middle } \\
\text { interfaces }\end{array}$ & 15 & $5 \%$ & $1.05 \times \mathrm{G}_{\mathrm{Ic}}$ & $\begin{array}{l}1.05 \mathrm{x} \\
\mathrm{G}_{\mathrm{IIc}}\end{array}$ \\
\hline Thin nanostitched $10 \%$ & $\left([0 / 90 / \pm 45]_{6}\right)_{\mathrm{s}}$ & $\begin{array}{l}\text { Middle } \\
\text { interfaces }\end{array}$ & 15 & $10 \%$ & $1.10 \times \mathrm{G}_{\mathrm{Ic}}$ & $\begin{array}{l}1.10 \mathrm{x} \\
\mathrm{G}_{\mathrm{IIc}}\end{array}$ \\
\hline Thin nanostitched $15 \%$ & $\left([0 / 90 / \pm 45]_{6}\right)_{\mathrm{s}}$ & $\begin{array}{l}\text { Middle } \\
\text { interfaces }\end{array}$ & 15 & $15 \%$ & $1.15 \times \mathrm{G}_{\mathrm{Ic}}$ & $\begin{array}{l}1.15 \mathrm{x} \\
\mathrm{G}_{\mathrm{IIc}}\end{array}$ \\
\hline Thin nanostitched $20 \%$ & $\left([0 / 90 / \pm 45]_{6}\right)_{\mathrm{s}}$ & $\begin{array}{l}\text { Middle } \\
\text { interfaces }\end{array}$ & 15 & $20 \%$ & $1.20 \mathrm{x} \mathrm{G}_{\mathrm{Ic}}$ & $\begin{array}{l}1.20 \mathrm{x} \\
\mathrm{G}_{\text {IIc }} \\
\end{array}$ \\
\hline
\end{tabular}

Table S1 Interlaminar properties used in short beam shear simulations.

Since the HTS40/Q-1112 material system is not fully characterized, the enhancement factor was determined by comparing the experimental and numerical damage extension after failure on the Thin nanostitched configuration. It was concluded that an increase of $10-15 \%$ on the fracture toughness of the middle interfaces is enough to shift the damage away from the centre as seen experimentally and it is therefore suggested that the nanostitch improves the mode II fracture toughness by a factor of 1.10-1.15 as shown in Fig S3. 


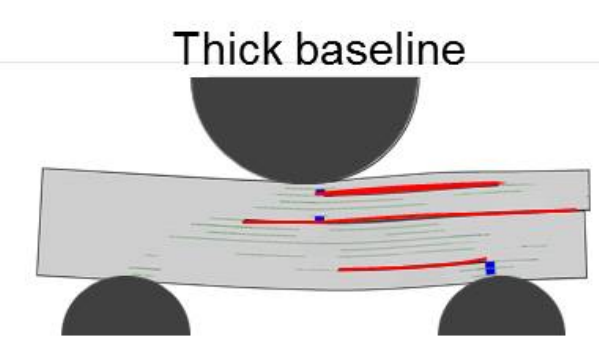

Thin nanostitched 5\%

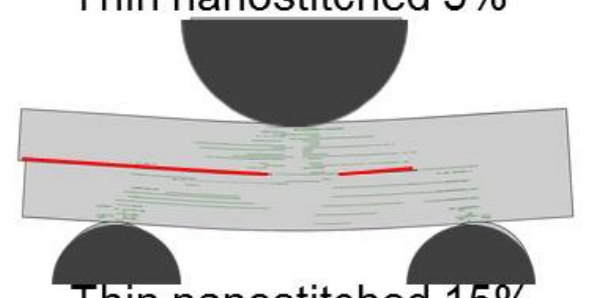

Thin nanostitched $15 \%$

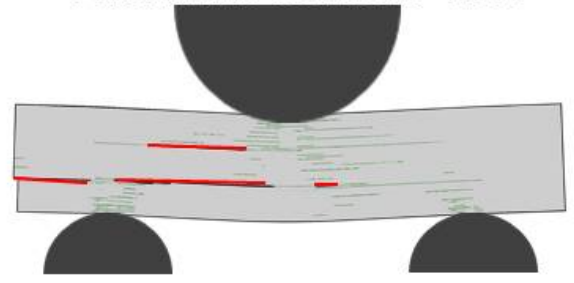

Delamination

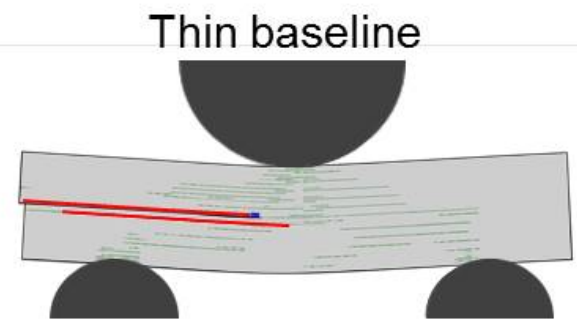

Thin nanostitched 10\%

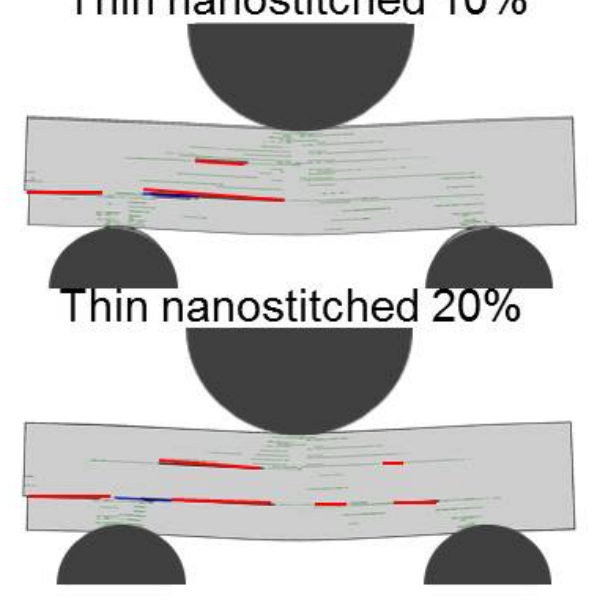

Damaged Elements (simulation)

Fig. S3 Simulated interfacial damaged as function of interlaminar toughness improvement. 